\title{
Wellness and Motivation in a Physical Education Course Over a Semester: Examining the Interaction Effects that Motivation has on Wellness Outcomes
}

\author{
John Lothes II, LPA, Ed.D. \\ University of North Carolina Wilmington \\ School of Health and Applied Human Sciences \\ Rachel Kantor, M.A. \\ University of North Carolina Wilmington \\ Dept of Psychology
}

\begin{abstract}
Objective: This study reports the results that physical education classes have on college students' overall wellbeing and motivation over the course of a semester. This study examines the pre/post outcomes of a physical education course on 12 dimensions of wellness and motivation from the start of the semester to the end of the semester.

Participants: College students $(N=1193)$ taking Physical Education 101 (PED101) over the course of a semester.

Methods: Beginning (pre) and end (post) of the semester assessments for wellbeing and motivation were conducted using the Wellness Inventory. Quantitative outcomes from the Wellness Inventory were compared pre/post as well as demographic variables (e.g., gender \& exercise frequency). Regression analysis was also conducted to examine how motivation may affect wellness.

Results: All 12 dimensions of wellness and motivation showed increases from the start of the semester to the end of the semester. Motivation was also positively correlated with increases in wellness scores. The results found statistically significant changes between the pre- and post-assessments for all dimensions of wellness outcomes and motivation scores. There were also significant changes between the pre- and post-assessments when investigating differences based on sex.

Conclusion: PED101 courses can be useful interventions to help move college students towards wellness.
\end{abstract}

Submitted 23 December 2020: accepted 28 January 2021

Keywords: health education, college student health, wellness, wellness inventory, motivation in wellness

For the first time in almost 100 years, the Center for Disease Control (CDC, 2018) has predicted a drop in life expectancy for U.S. residents, Robert Redfield of the CDC states:

The latest CDC data show that the U.S. life expectancy has declined over the past few years. Tragically, this troubling trend is largely driven by deaths from drug overdose and suicide. Life expectancy gives us a snapshot of the Nation's overall health and these sobering statistics are a wakeup call that we are 
losing too many Americans, too early and too often, to conditions that are preventable. CDC is committed to putting science into action to protect U.S. health, but we must all work together to reverse this trend and help ensure that all Americans live longer and healthier lives. (CDC, 2018)

Research has shown that positive subjective wellbeing serves as a protective mechanism for health. Research on motivation has largely looked at motivation as a singular entity, it either exists, or it does not, and if it does exist, it only exists to some degree (Ryan \& Deci, 2017). Even as early as 1908, Yerkes and Dodson developed a model for motivation to the level of performance. They proposed an inverted $U$ theory to motivation, as low levels of motivation tend to produce poorer outcomes, while moderate amounts of motivation produced maxim performance and large amounts of motivation produced poorer outcomes. They argued that too much arousal may result in diminished outcomes. In the 1960s and 1970s, the cognitive theories of motivation surfaced, and two theories predominated the field, expectancy-valence theory (Vroom, 1964) and cognitive-behavioral theories (Bandura, 1977). The expectancyvalence theory predicts behavior as a result of the amount of motivation, which is believed to be the result of the valence or psychological value of the outcome multiplied by the probability of being able to attain those outcomes. Likewise, cognitive-behavioral theories predict motivation based on the strength of one's belief in their ability to attain these outcomes (Seligman, 1975). While Self-Determination Theory postulates that motivation is not a unitary concept, but rather, is driven by one's values and interests (Ryan \& Deci, 2017).

Wellbeing research has clearly established a relationship between impaired wellbeing and negative psychological symptoms, premature mortality, disease, disability, and chronic disorders (Lyubomirsky, King, \& Dier, 2005; Steptoe, Deaton, \& Stone, 2015). The relationship between decreased levels of wellbeing and increases in mental health issues, missed workdays, and suicide risk is alarming and needs to be addressed. Positive subjective wellbeing has been associated with work productivity, decreased mental health issues, and longevity of life (Keyes et al., 2012; Keyes \& Grzywacz, 2005; Keyes, \& Simoes, 2012). This study examines how a semester long Physical Education (PED101) class may play a role in increasing wellbeing and motivation for wellbeing in college students.

\section{BACKGROUND}

Understanding that motivation plays a role in getting people to understand models of wellbeing is crucial in promoting wellness. The biopsychosocial model as proposed by Engel $(1977 ; 1980)$ was first presented as an extension to the medical model that existed at the time. While the medical model focused more on physical wellbeing of the person, the biopsychosocial model argued for a more holistic view of a person's wellbeing. As time progressed, so did the model, with Gordon (1990) suggesting the addition of a spiritual aspect to be included in wellbeing. In the early 80s, Travis and Ryan (1981; 2004) developed the Wellness Inventory to assess wellness on 12 dimensions: selfresponsibility \& love; breathing; sensing; eating; moving; feeling; thinking; playing and working; communicating; intimacy; finding meaning; and transcending. The Wellness Inventory captures a snapshot of the recommended biosocial model and the recommended expansion of issues of spirituality (Gordon, 1990) by including scales that assess Finding Meaning and Transcending. Travis first proposed a wellness continuum in 1977 and this model has continued to evolve with current theories (Edelman \& Mandle, 2017) of wellness. Figure 1 presents Edelman's and Mandle's current view of the illness/wellness model. 


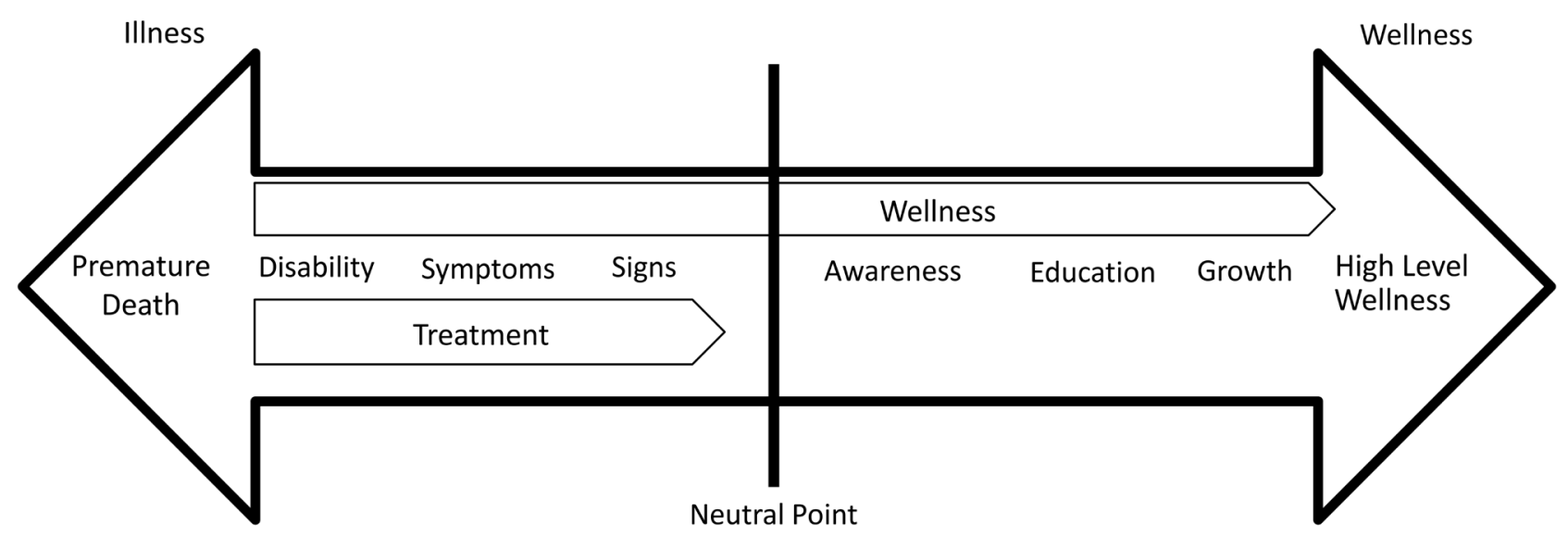

Figure 1. Continuum of Wellness (Edelman \& Mandle, 2017).

College student wellness has been a growing focus of recent researchers (Burris, Brechting, Salsman, \& Carlson, 2009) as they attempt to understand what factors play a role in student health and wellbeing (Wahl-Alexander \& Chomentowski, 2018). With the current life expectancy drop as suggested by the CDC (2018), it is now more important than ever to find ways to effectively point college students in the direction of wellness and not away from it. Researchers have examined different aspects of wellness, including demographic variables (Baldwin, Towler, Oliver, \& Datta, 2017; Burris et al., 2009; Lothes \& Nanney, 2019), to see which groups or characteristics may be associated with higher rates of wellness or illness. With the continued trend for college students to engage in sedentary (Buckworth \& Nigg, 2004) and unhealthy behavioral patterns, universities need to design and implement effective ways to encourage students to engage in activities that promote wellness.

A student's time during college not only allows them to grow as emerging adults, it also has the potential to lay the foundation for what healthy or unhealthy lifestyle habits will develop across their lifespan (American College Health Association [ACHA], 2010). Cardinal (2014) has asked researchers and colleges to engage in a call to action to study student wellbeing and examine how we can have an effect on college students' health and wellbeing beyond teaching about diet and exercise. Cardinal (2014) has suggested that researchers look at college students wellbeing on a more holistic level. Hettler (1984) proposed a holistic approach that consisted of six broad dimensions of healthrelated behaviors: physical wellness; emotional wellness; spiritual wellness; social wellness; occupational wellness; and intellectual wellness. Promoting a holistic approach to wellbeing has been associated with improved psychological functioning and serves as a protective mechanism against physical disorders (Gieck, \& Olsen, 2007). Thus, aligning with Travis's (1981) proposed model.

Lothes and Nanney (2019) conducted an end of semester assessment with college students $(N=1,544)$ using the Wellness Inventory. Their results found that among demographic variables, such as age and sex, there were no moderating effects on the 12 dimensions of wellness measured by Travis's Wellness Inventory (1981). However, selfreported health status and frequency of exercise both showed significant differences on all 12 dimensions on outcomes in the Wellness Inventory. Students who reported being in excellent or good health exhibited higher ratings of wellness than students reporting to be in fair or poor health. Students that reported higher levels of exercise frequency (daily, 4 - 6 x week, 3 x week) also reported significantly higher ratings of wellness than students who reported exercising less frequently ( $2 \mathrm{x}$ week, $1 \mathrm{x}$ week, \& $1 \mathrm{x}$ month or less) on most dimensions. Lothes' and Nanney's (2019) research found that age and sex may not be as important in wellness when compared to health status 
and frequency of exercise. These outcomes are promising as we can work to change student frequency of exercise patterns and student health status through educational means. One potential downside to Lothes' and Nanney's research, however, is that they did not conduct a pre/post assessment to see if any changes actually occurred throughout the semester. Lothes' and Nanney's (2019) outcomes did help to provide insights into college student wellness ratings and outcome differences in the wellness inventory. Baldwin and colleagues (2017) examined the difference of five wellness factors (i.e., physical, emotional, social, intellectual, and occupational) between liberal arts college students and research university students on demographic data outcomes. The researchers looked at differences between liberal arts college students $(N=126)$ and research university students $(N=85)$. Carnegie classification, a framework for classifying comparable colleges and universities, was given for an operational definition of "research university" for this study. Their results showed that there were significant differences between students that were working (i.e., employed) or not working on ratings of overall wellness. Working students had higher ratings of self-efficacy than students that were not working at the time. Working students also reported a significantly lower frequency of exercise than students not working. Sex differences were also found in this study, i.e., female students reported engaging in less physical activity and lower overall health related behaviors than male students. While this study does shed light on wellbeing differences between college students, like Lothes and Nanney's (2019) study, it only reveals a onetime assessment without providing any insight into possible interventions that could be adopted to encourage college students and enhance factors of wellbeing. The current study seeks to expand on this literature gap where studies are examining differences between demographic variables in the absence of possible interventions for change.

It has been evident over the last decade that health behavior patterns established in college have been shown to relate to health behavior patterns later in life (Hultquist, Duckham, Stinson, \& Thompson, 2009). Forming effective and healthy behavior patterns in college or emerging adulthood is pivotal in helping people maintain healthy lifestyle habits as they get older. From a health educators' perspective, we should be trying to help implement effective strategies that get students pointed in the direction of wellness and away from the direction of illness. Better mechanism of teaching and education on the matters of health and wellbeing play a pivotal role in encouraging students to move towards wellness (Rouse \& Biddle, 2009).

The ACHA (2010; 2017) has identified physical inactivity as a continued concern for this population and has called for immediate attention on the matter. An increased number of college students are adopting sedentary and unhealthy lifestyles during this stage of life at an alarming rate (Keating, Guan, Pinero, \& Bridges, 2005). According to the CDC (2018), this rate is leading to decreased levels of life expectancy predicting that the current generation may not live longer than the previous generation.

While in college, students are learning to balance many different priorities including work, school, relationships, free-time, and self-care. For some of these students, this may be the first time ever they are trying to figure out this balance. Providing students education and knowledge on facets of wellbeing is vital during this stage of development. Through effective and quality educational measures, we can teach students about the effects of healthy habits on their wellbeing, ultimately laying the foundation for future health behaviors. Because there are many factors that play a role in college students' wellbeing (Downes, 2015), it would be wise to take a multidimensional approach to student wellness (Travis \& Ryan, 2004) and not just focus on one or two aspects.

Beauchemin, Gibbs, \& Granello (2018) did a research review of different study formats for the delivery of college wellness courses. Their results found that there was a lack of rigorous research designs, a lack of evidence-based or 
wellness-based models being used, that there were challenges associated with consensus and conceptualization of wellness amongst researchers, and fidelity and replicability issues. Cardinal's (2014) "call-to-action" of educators and researchers is an attempt to attract and keep people more physically active across the lifespan. While the focus of this study was not physical activity alone, it did heed this call to action by Cardinal about trying to help college aged individuals find a path to wellness across their lifespan. Myers and Sweeney (2004) proposed an evidence based multidimensional model that is based on characteristics of healthy individuals and focuses on a strength-based, choiceoriented model of wellness that is grounded in sound theory. Their argument is that this model can be used with or without assessment tools to help understand different components of wellness for people. The interaction of these components and the manner in which positive change may be facilitated is critical to helping others understand their own wellbeing. In their literature review the authors discuss different wellness models and possible influences into one's wellness. One theoretical model they discuss is that of the Wheel of Wellness and how its 12 components of wellness (e.g., family, spirituality, education, business, government and community) influence behavior.

Travis $(1981 ; 2004)$ contends that wellness is bi-directional, either we are facing towards illness, or towards wellness. Through education we can help turn individuals from directions of illness (weaknesses) towards the direction of wellness (strengths) by focusing on factors that individuals may have more control over in the 12-dimensional model. Travis $(1981 ; 2004)$ argues that wellness is a continued process, not a static state. While many assume the absence of illness means wellness, Travis (2004) believes this is not the case. He believes there are varying degrees of both illness and wellness. The Illness-Wellness Continuum (Travis, 2004) is a graphic representation of illness and wellness. In this model an individual can move past the neutral point to either higher degrees of illness or wellness. In the Illness-Wellness continuum it is possible to not have physical symptoms and experience depression, boredom, anxiety, unhappiness, or other negative wellness related outcomes. As a result of continued experience of these negative emotions, an individual may develop physical and mental health symptoms. For college aged individuals getting pointed towards wellness could potentially prevent health problems that occur later in life that are related to poor health habits like heart-disease, cancer, anxiety, obesity, etc. Higher levels of wellness involve self-care activities that may include such things as taking care of oneself physically, effectively experiencing and expressing emotions, flexing one's mind through creative endeavors, and having some form spiritually practice. Travis argues that wellness is not so much about where a person stands on the continuum, but which direction they are facing.

Moving from the right to the left of the model indicates a progressively deteriorating state of wellbeing and wellness. While moving to the right of the continuum indicates increasing levels of health and wellbeing. The treatment paradigm as proposed by the medical model (Kirsten, Van der Walt, \& Viljoen, 2009) postulates that drugs, surgery, and psychotherapy can bring people to a neutral point, thus resulting in reduced or eliminated disease symptomology. The medical model falls short of the robustness that wellness theory brings. The wellness paradigm encourages individuals to move as far forward toward wellness as possible. Of primary interest for this study was that of the college student population and helping direct participants towards wellness and away from illness.

According to the U.S. Department of Health and Human Services (DHSS, 2019) adults should be moving more and sitting less throughout the day. They advise that adults that engage in some form of moderate to vigorous physical activity will gain some health benefits. The DHSS recommends that adults engage in at least 150 to 300 minutes of moderately intense exercise every week, 75 to 150 minutes of vigorously intense exercise every week, or a combination of both moderate and intense exercise throughout the week. It is also recommended that adults engage in a combination of both aerobic exercise and muscle-strengthening activities two or more times a week. The World 
Health Organization (WHO, 2010) recommends that adults 18 - 64 years old should engage in at least 150 minutes of moderate intensity aerobic physical activity or engage in at least 75 minutes of vigorously intense aerobic physical activity throughout the week, or some form of a combination of both moderate and vigorously intense exercise throughout the week. College level physical education courses can provide a platform to shape young adults towards more wellness-related behaviors as suggested by the DHSS and the WHO. This study examines the outcomes of when you combine a physical education course that encourages movement to meet the above expected criteria along with educational assignments that provide information on development in the different dimensions of wellness.

The purpose of this study was to determine if there were changes in wellness from PED 101 courses at a southeast university in United States (IRB approval \#18-0232). An examination of overall changes in the 12 dimensions of wellness was conducted, as was the examination of differences in motivation scores from start of the semester to the end of the semester. Different demographic variables were assessed to gauge whether there were differences in the 12 wellness outcomes for college students at the post-assessment phase. The Wellness Inventory (Travis, 2004) was used to assess students at the beginning (pre) and end (post) of the semester on 12 dimensions of wellness.

Our hypotheses were as follows:

$\mathrm{H}_{1}$ : There will be changes in all 12 dimensions of wellness from the start of the semester to the end of the semester for all students combined.

$\mathrm{H}_{2}$ : Males and Females will show improvements in wellness dimensions from start of the semester to the end of the semester.

$\mathrm{H}_{3}$ : Overall motivation scores will change from the start of the semester to the end of the semester $\mathrm{H}_{4}$ : Motivation scores will be related to increases in wellness scores

\section{METHODS}

\section{Participants}

PED101 students $(N=1193)$ were assessed at the beginning of the semester (January 2019) for each dimension of wellness and then again at the end of the semester (May 2019). The courses were online with resources available through the Wellness Inventory for Dimensions of Wellness and an eBook was also used through Tophat for students to work through tutorials online about health and wellness.

\section{Demographics}

Demographics were recorded by student self-report. Thirty-nine percent identified as Male, $60.3 \%$ identified as Female, and no participants identified as other. Ninety-six perfect of the participants were between 18 and 24 years old, $0.6 \%$ were between $35-44$, and $0.1 \%$ reported being between $45-54$. In regards to frequency of exercise, 10.1\% of participants reported exercising daily, 22.7\% exercised 4-6 times a week, 22.4\% exercised three times a week, $21.3 \%$ exercised twice a week, $13.9 \%$ exercised once a week, and $9.6 \%$ reported exercising once a month or less. Since the demographic questions were not required to be answered by the wellness inventory, there is an uneven number of demographic categories. Health status was a onetime self-report during the initial assessment, as students ranked themselves in categories of excellent, good, fair, or poor based on their perceptions of their current health. 


\section{Course Description}

Each class was a two-credit hybrid course that met the physical activity recommendations suggested by the Physical Activity Guidelines for Americans (DHHS, 2019), i.e., 150 mins each week. The course consisted of two parts: (1) a face-to-face laboratory and (2) an online lecture component. In the face-to-face laboratory, students signed up for different classes offered from a menu of approximately 40 classes, e.g., martial arts classes, strength and condition classes, aerobic exercise classes, and yoga. The face-to-face lab consisted of assignments and readings that were conducted through Tophat's online book (Nanney, 2019). There was also an online lecture component that addressed educational activities on the specific 12 dimensions of wellness (Travis \& Ryan, 2004). Students accessed study center tutorials through the wellness inventory about different dimensions of wellness. Throughout the semester students created action steps to help guide them on a path towards wellness through a process of implementing small steps to continuous improvement (Cardinal, Park, Kim, \& Cardinal, 2015).

This course consisted of participation in a physical activity component where students attended a face-to-face physical activity class. Along with the face-to-face class, there were educational materials designed as assignments to increase awareness and development of the physical, spiritual, emotional, social, and intellectual components of wellness, becoming an informed health consumer, and the application of healthy lifestyle choices for improved quality of life. The PED 101 is a 2-credit class that is required of all university students and meets the University Studies Lifespan Wellness requirement.

\section{Measures}

Wellness Inventory. The wellness inventory was used at the beginning and the end of the semester to assess overall student ratings on the 12 dimensions of wellness. The Wellness Inventory has been shown to be both reliable and valid in the assessment of overall college student population (Travis \& Ryan, 2004)

The 12 dimensions of wellness assessed by the wellness inventory include (Travis \& Ryan, 2004)

1. Self-Responsibility and Love which entails expressing ideas and emotions in ways that communicate with others effectively while maintaining faithfulness to self.

2. Breathing which assesses how factors of breathing affect output or general metabolism and a person's ability to work, play and communicate.

3. Sensing which is comprised of developing skills and becoming aware of how to appreciate and use our sensory input efficiently and creatively.

4. Eating which deals with assessing and teaching students how food not only affects physical health, but how it plays a role on emotions.

5. Moving which addresses how movement of the body plays a role in holistic wellbeing, how movement affects both physical and emotional health.

6. Factors of Feeling which is about becoming aware of our emotions and feelings and how they may have an affect us.

7. Thinking which focuses on how thinking can be affected by both emotional and physical health and how improved health can relate to improved thinking.

8. Playing and Working which focuses on recapturing the spirit of play and how this can bring balance to people's lives when they are overwhelmed from work and other responsibilities. 
9. Communicating which focuses primarily on verbal communication, and how we talk to ourselves as well as how we speak with others, while also examining some of the potentials for breakdown in communication that may occur.

10. Intimacy which addresses how we connect with others and build relationships effectively.

11. Finding Meaning which helps assess how people find meaning in life and offers suggestions of activities to help them find some meaning and purpose in their life.

12. Transcending which is about finding that peak experience or flow state, it is an experience of being fully awake and engaged in the present moment.

The wellness inventory is a 10-point Likert-type scale with no reverse scored items ranging from 0 (the lowest point) to 10 (the highest point).

\section{Statistical Analysis}

Scores for the 12 dimensions were collected from the Wellness Inventory database of all the classes. There were no identifying factors such as names or date of birth available, so confidentiality was maintained. To analyze the data, paired $t$-tests were conducted on the overall wellness inventory output to assess overall differences in wellness inventory dimension changes. Paired $t$-tests were used to compute differences in demographic variables for gender and frequency of exercise of the students. ANOVAs were also conducted to see if there were any differences in Wellness Inventory scores at the pre-assessment and post-assessment between demographic variables. Regressions were conducted to see if motivation scores influenced wellness score changes.

\section{RESULTS}

\section{Overall Wellness Scores}

A series of paired sample $t$-tests were run to determine if there was a significant increase in all 12 dimensions of wellness from pre-assessment to post-assessment. A significant difference was found between pre-semester scores and post-semester scores for each dimension (See Table 1).

Table 1

Overall Pre/Post Wellness Scores

\begin{tabular}{|c|c|c|c|c|c|c|c|}
\hline \multirow{2}{*}{$\begin{array}{l}\text { Dimension } \\
(\mathrm{N}=1193)\end{array}$} & \multicolumn{2}{|l|}{ Pre } & \multicolumn{2}{|l|}{ Post } & \multirow[b]{2}{*}{ t-value } & \multirow[b]{2}{*}{$p$} & \multirow[b]{2}{*}{$d$} \\
\hline & $\underline{\text { Mean }}$ & $\underline{\mathrm{SD}}$ & $\underline{\text { Mean }}$ & $\underline{\mathrm{SD}}$ & & & \\
\hline \multicolumn{8}{|c|}{ Self-Resp \& Love } \\
\hline & 72.79 & 12.34 & 79.95 & 12.69 & 19.55 & $.0001 * * *$ & 0.57 \\
\hline Breathing & 55.68 & 17.34 & 71.73 & 17.13 & 32.72 & $.0001 * * *$ & 0.93 \\
\hline Sensing & 65.20 & 14.54 & 76.25 & 14.55 & 26.45 & $.0001 * * *$ & 0.76 \\
\hline Eating & 54.37 & 17.66 & 67.04 & 17.86 & 26.36 & $.0001 * * *$ & 0.71 \\
\hline Moving & 60.75 & 19.59 & 74.08 & 17.39 & 26.56 & $.0001^{* * *}$ & 0.72 \\
\hline Feeling & 64.97 & 16.46 & 74.73 & 16.77 & 21.69 & $.0001^{* * *}$ & 0.59 \\
\hline
\end{tabular}




\begin{tabular}{llllllll} 
Thinking & 62.18 & 16.45 & 74.07 & 16.42 & 25.54 & $.0001^{* * *}$ & 0.72 \\
Playing \& Working & 63.49 & 17.32 & 75.23 & 16.63 & 25.68 & $.0001^{* * *}$ & 0.69 \\
Communicating & 75.07 & 14.04 & 81.00 & 13.96 & 15.79 & $.0001^{* * *}$ & 0.42 \\
Intimacy & 76.57 & 15.22 & 82.55 & 14.78 & 14.75 & $.0001^{* * *}$ & 0.40 \\
Finding Meaning & 67.52 & 16.95 & 76.72 & 16.47 & 20.85 & $.0001^{* * *}$ & 0.55 \\
Transcending & 65.75 & 16.80 & 76.19 & 16.85 & 23.91 & $.0001^{* * *}$ & 0.62 \\
\hline
\end{tabular}

Note. $*$ indicates $p<.01, * *$ indicates $p<.001, * * *$ indicates $p<.0001$

\section{Sex}

In order to determine if changes in dimension scores differed by gender, paired sample $t$-tests were conducted only using male participants and then only using female participants. When looking at gender, both males (Table 2) and females (Table 3) showed significant changes from pre-assessment to post-assessment.

Table 2

Males Pre/Post

\begin{tabular}{|c|c|c|c|c|c|c|c|}
\hline \multirow{2}{*}{$\begin{array}{l}\text { Dimension } \\
(\mathrm{N}=474)\end{array}$} & \multicolumn{2}{|l|}{ Pre } & \multicolumn{2}{|l|}{ Post } & \multirow[b]{2}{*}{ t-value } & \multirow[b]{2}{*}{$P$} & \multirow[b]{2}{*}{$d$} \\
\hline & $\underline{\text { Mean }}$ & $\underline{\mathrm{SD}}$ & $\underline{\text { Mean }}$ & $\underline{\mathrm{SD}}$ & & & \\
\hline \multicolumn{8}{|l|}{ Self-Resp \& Love } \\
\hline & 72.28 & 12.31 & 79.12 & 13.22 & 11.44 & $.0001 * * *$ & 0.54 \\
\hline Breathing & 56.80 & 17.41 & 72.13 & 17.50 & 19.98 & $.0001 * * *$ & 0.88 \\
\hline Sensing & 66.31 & 14.80 & 76.52 & 14.98 & 14.09 & $.0001 * * *$ & 0.69 \\
\hline Eating & 54.16 & 17.60 & 67.22 & 18.38 & 16.34 & $.0001 * * *$ & 0.73 \\
\hline Moving & 62.57 & 19.04 & 74.60 & 17.51 & 14.38 & $.0001 * * *$ & 0.66 \\
\hline Feeling & 64.71 & 16.20 & 74.37 & 17.12 & 13.28 & $.0001 * * *$ & 0.58 \\
\hline Thinking & 63.95 & 16.03 & 74.54 & 16.72 & 14.46 & $.0001 * * *$ & 0.65 \\
\hline Playing \& Working & 65.30 & 16.57 & 75.61 & 16.67 & 14.18 & $.0001 * * *$ & 0.62 \\
\hline Communicating & 74.00 & 14.16 & 79.17 & 15.24 & 7.93 & $.0001 * * *$ & 0.35 \\
\hline Intimacy & 74.72 & 15.16 & 80.18 & 15.77 & 7.82 & $.0001 * * *$ & 0.35 \\
\hline Finding Meaning & 68.67 & 16.36 & 76.60 & 16.94 & 10.61 & $.0001 * * *$ & 0.48 \\
\hline Transcending & 65.92 & 16.62 & 75.37 & 17.20 & 13.40 & $.0001 * * *$ & 0.56 \\
\hline
\end{tabular}

Note. $*$ indicates $p<.01, * *$ indicates $p<.001, * * *$ indicates $p<.0001$ 
Table 3

Females Pre/Post

\begin{tabular}{|c|c|c|c|c|c|c|c|}
\hline \multirow{2}{*}{$\begin{array}{l}\text { Dimension } \\
(\mathrm{N}=719)\end{array}$} & \multicolumn{2}{|l|}{ Pre } & \multicolumn{2}{|l|}{ Post } & \multirow[b]{2}{*}{ t-value } & \multirow[b]{2}{*}{$p$} & \multirow[b]{2}{*}{$d$} \\
\hline & $\underline{\text { Mean }}$ & $\underline{\mathrm{SD}}$ & $\underline{\text { Mean }}$ & $\underline{\mathrm{SD}}$ & & & \\
\hline \multicolumn{8}{|l|}{ Self-Resp \& Love } \\
\hline & 73.12 & 12.36 & 80.50 & 12.30 & 15.93 & $.0001 * * *$ & 0.60 \\
\hline Breathing & 54.95 & 17.27 & 71.46 & 16.90 & 25.92 & $.0001 * * *$ & 0.97 \\
\hline Sensing & 64.47 & 14.34 & 76.08 & 14.27 & 23.13 & $.0001 * * *$ & 0.81 \\
\hline Eating & 54.51 & 17.71 & 66.92 & 17.52 & 20.72 & $.0001 * * *$ & 0.70 \\
\hline Moving & 59.54 & 19.87 & 73.75 & 17.32 & 22.79 & $.0001 * * *$ & 0.76 \\
\hline Feeling & 65.15 & 16.64 & 74.96 & 16.54 & 17.16 & $.0001 * * *$ & 0.59 \\
\hline Thinking & 61.01 & 16.36 & 73.76 & 16.21 & 21.19 & $.0001 * * *$ & 0.78 \\
\hline Playing \& Working & 62.31 & 17.71 & 74.98 & 16.61 & 21.65 & $.0001 * * *$ & 0.74 \\
\hline Communicating & 75.37 & 13.93 & 82.20 & 12.93 & 14.26 & $.0001 * * *$ & 0.51 \\
\hline Intimacy & 77.79 & 15.15 & 84.12 & 13.88 & 12.90 & $.0001 * * *$ & 0.44 \\
\hline Finding Meaning & 66.78 & 17.30 & 76.99 & 16.16 & 18.45 & $.0001 * * *$ & 0.65 \\
\hline Transcending & 65.64 & 16.92 & 76.73 & 16.61 & 20.00 & $.0001 * * *$ & 0.66 \\
\hline
\end{tabular}

Note. $*$ indicates $p<.01, * *$ indicates $p<.001, * * *$ indicates $p<.0001$

Pre-assessment self-reported gender ratings differences (see Tables 3 \& 4 for means and standard deviations). There were no differences between genders for ratings of self-responsibility, breathing, eating, feeling, finding meaning and transcending. There were significant differences between genders where males reported significantly higher scores for: sensing, $\mathrm{F}(1,1191)=4.57, p<0.03$; moving, $\mathrm{F}(1,1191)=6.88, p<.009$; thinking, $\mathrm{F}(1$, $1191)=9.19, p<.003$; and playing and working, $\mathrm{F}(1,1191)=8.57, p<.004$. Females had significantly higher scores for communicating, $\mathrm{F}(1,1191)=4.52, p<.03$, and intimacy, $\mathrm{F}(1,1191)=11.73, p<.0006$.

Post-assessment self-reported gender ratings differences (see Tables $3 \& 4$ for means and standard deviations). There were no differences between genders for ratings of self-responsibility, breathing, sensing, eating, moving, feeling, thinking, play and work, finding meaning, and transcending. There were significant differences between genders for sensing, communicating, $\mathrm{F}(1,1191)=13.57, p<.0002$, and intimacy, $\mathrm{F}(1,1191)=20.57, p<$ .0001 , where females reported significantly higher scores than males.

Pre-Assessment Self-Reported Health Ratings Differences. Between analysis results on pre-assessment outcomes for all groups showed that students that self-reported higher rates of exercise frequency also reported higher wellness ratings. Students reporting high and moderate levels of exercise also reported higher wellness rating scores than students that reported low exercise frequency. The results for most of the scales do show a trend for high exercise frequency students reporting higher scores in all 12 dimensions than low exercise frequency students. However, high exercise frequency students did not report higher levels of wellness on the dimensions for sensing, feeling, communicating, intimacy, or transcending than students that reported moderate exercise frequency. 
High vs. moderate levels of exercise. One-way ANOVAs were run, per dimension, to see if pre-semester wellness scores differed by exercise frequency, comparing high level of exercise frequency to moderate levels of exercise frequency. Students that identified as exercising at a high level of frequency (daily or 4-6 x week) had significantly higher wellness scores than those that reported exercising moderately ( $2 \mathrm{x}$ week or $3 \mathrm{x}$ week; Table 4$)$.

Table 4

Pre-High vs. Pre-Moderate Frequency of Exercise

\begin{tabular}{|c|c|c|c|c|c|c|}
\hline \multirow[t]{2}{*}{$\begin{array}{l}\text { Dimensions } \\
(\mathrm{N}=392)\end{array}$} & \multicolumn{2}{|c|}{ High Frequency } & \multicolumn{4}{|c|}{$\begin{array}{l}\text { Moderate } \\
\text { Frequency }\end{array}$} \\
\hline & Mean & $\underline{\mathrm{SD}}$ & $\underline{\text { Mean }}$ & $\underline{\mathrm{SD}}$ & $F$ & $p$ \\
\hline \multicolumn{7}{|l|}{ Self-Resp \& Love } \\
\hline & 75.09 & 12.06 & 72.31 & 11.94 & 8.48 & $.004 * *$ \\
\hline Breathing & 58.88 & 18.09 & 55.99 & 16.30 & 6.39 & $.01 *$ \\
\hline Sensing & 67.40 & 14.54 & 65.64 & 13.80 & 3.48 & .06 \\
\hline Eating & 60.73 & 18.20 & 54.40 & 16.21 & 30.70 & $.0001 * * *$ \\
\hline Moving & 73.75 & 14.76 & 60.27 & 16.48 & 163.60 & $.0001 * * *$ \\
\hline Feeling & 66.98 & 16.80 & 65.89 & 14.67 & 1.03 & .31 \\
\hline Thinking & 65.32 & 17.13 & 62.87 & 15.41 & 5.17 & $.02 * *$ \\
\hline Playing \& Working & 67.77 & 16.93 & 64.10 & 16.55 & 10.77 & $.0001 * * *$ \\
\hline Communicating & 76.71 & 13.92 & 76.02 & 13.41 & 0.57 & .45 \\
\hline Intimacy & 78.40 & 14.57 & 77.52 & 14.26 & 0.83 & .36 \\
\hline Finding Meaning & 71.55 & 16.82 & 67.87 & 15.48 & 11.72 & $.001 * *$ \\
\hline Transcending & 68.50 & 17.21 & 67.11 & 15.66 & 1.64 & .20 \\
\hline
\end{tabular}

Note. $*$ indicates $p<.01, * *$ indicates $p<.001, * * *$ indicates $p<.0001$

High vs. low levels of exercise. One-way ANOVAs were conducted, per dimension, to see if pre-semester wellness scores differed by exercise frequency, comparing high levels of exercise frequency to low levels of exercise frequency. Students that identified as exercising at a high level of frequency (daily or 4-6 x week) had significantly higher wellness scores than those that reported exercising at a low frequency (1 x week or $1 \mathrm{x}$ month; Table 5).

Table 5

Pre-High vs. Pre-Low Frequency of Exercise

\begin{tabular}{|c|c|c|c|c|c|c|}
\hline \multirow{2}{*}{$\begin{array}{l}\text { Dimensions } \\
(\mathrm{N}=392)\end{array}$} & \multicolumn{2}{|c|}{ High Frequency } & \multicolumn{2}{|c|}{ Low Frequency } & \multirow[b]{2}{*}{$F$} & \multirow[b]{2}{*}{$p$} \\
\hline & Mean & $\underline{\text { SD }}$ & Mean & $\underline{\text { SD }}$ & & \\
\hline \multicolumn{7}{|c|}{ Self-Resp \& Love } \\
\hline & 75.09 & 12.06 & 69.54 & 13.33 & 31.66 & $.0001^{* * *}$ \\
\hline \multirow[t]{2}{*}{ Breathing } & 58.88 & 18.09 & 50.62 & 17.05 & 35.72 & $.0001 * * *$ \\
\hline & \multicolumn{6}{|c|}{75} \\
\hline
\end{tabular}




\begin{tabular}{lllllll} 
Sensing & 67.40 & 14.54 & 61.32 & 15.18 & 27.48 & $.0001^{* * *}$ \\
Eating & 60.73 & 18.20 & 45.41 & 15.53 & 130.46 & $.0001^{* * *}$ \\
Moving & 73.75 & 14.76 & 43.44 & 17.03 & 605.24 & $.0001^{* * *}$ \\
Feeling & 66.98 & 16.80 & 60.46 & 16.63 & 24.79 & $.0001^{* * *}$ \\
Thinking & 65.32 & 17.13 & 56.49 & 15.99 & 45.92 & $.0001^{* *}$ \\
Playing \& Working & 67.77 & 16.93 & 56.39 & 14.09 & 73.20 & $.0001^{* * *}$ \\
Communicating & 76.71 & 13.92 & 71.00 & 14.61 & 26.36 & $.0001^{* * *}$ \\
Intimacy & 78.40 & 14.57 & 72.26 & 16.98 & 25.20 & $.0001^{* * *}$ \\
Finding Meaning & 71.55 & 16.82 & 61.21 & 17.95 & 58.35 & $.0001^{* * *}$ \\
Transcending & 68.50 & 17.21 & 59.40 & 16.85 & 46.50 & $.0001^{* * *}$ \\
\hline
\end{tabular}

Note. $*$ indicates $p<.01, * *$ indicates $p<.001, * * *$ indicates $p<.0001$

Moderate vs. low levels of exercise. One-way ANOVAs were conducted, per dimension, to see if pre-semester wellness scores differed per exercise frequency, comparing moderate level of exercise frequency to low levels of exercise. Students that identified as exercising at a moderate level of frequency had significantly higher wellness scores than those that reported exercising at a low frequency of exercise (Table 6).

Table 6

Pre-Moderate vs. Pre-Low Frequency of Exercise

\begin{tabular}{|c|c|c|c|c|c|c|}
\hline \multirow{2}{*}{$\begin{array}{l}\text { Dimensions } \\
(\mathrm{N}=392)\end{array}$} & \multicolumn{2}{|c|}{ High Frequency } & \multicolumn{2}{|c|}{ Low Frequency } & \multirow[b]{2}{*}{$F$} & \multirow[b]{2}{*}{$p$} \\
\hline & $\underline{\text { Mean }}$ & $\underline{\mathrm{SD}}$ & $\underline{\text { Mean }}$ & $\underline{\mathrm{SD}}$ & & \\
\hline \multicolumn{7}{|l|}{ Self-Resp \& Love } \\
\hline & 72.31 & 11.94 & 69.54 & 13.33 & 12.84 & $.0001 * * *$ \\
\hline Breathing & 55.99 & 16.30 & 50.62 & 17.05 & 19.16 & $.0001 * * *$ \\
\hline Sensing & 65.64 & 13.80 & 61.32 & 15.18 & 16.59 & $.0001^{* * *}$ \\
\hline Eating & 54.40 & 16.21 & 45.41 & 15.53 & 57.63 & $.0001 * * *$ \\
\hline Moving & 60.27 & 16.48 & 43.44 & 17.03 & 185.42 & $.0001 * * *$ \\
\hline Feeling & 65.89 & 14.67 & 60.46 & 16.63 & 20.89 & $.0001^{* * *}$ \\
\hline Thinking & 62.87 & 15.41 & 56.49 & 15.99 & 30.37 & $.0001 * *$ \\
\hline Playing \& Working & 64.10 & 16.55 & 56.39 & 14.09 & 38.65 & $.0001 * * *$ \\
\hline Communicating & 76.02 & 13.41 & 71.00 & 14.61 & 24.01 & $.0001^{* * *}$ \\
\hline Intimacy & 77.52 & 14.26 & 72.26 & 16.98 & 21.62 & $.0001 * * *$ \\
\hline Finding Meaning & 67.87 & 15.48 & 61.21 & 17.95 & 30.11 & $.0001^{* * *}$ \\
\hline Transcending & 67.11 & 15.66 & 59.40 & 16.85 & 42.15 & $.0001 * * *$ \\
\hline
\end{tabular}

Note. $*$ indicates $p<.01, * *$ indicates $p<.001, * * *$ indicates $p<.0001$ 


\section{Post-Assessment Self-Reported Health Ratings Differences (see Table 4 for Means and Standard Deviations)}

High vs. moderate levels of exercise. One-way ANOVAs were run, per dimension, to see if post-semester wellness scores differed by exercise frequency, comparing high level of exercise frequency to moderate levels of exercise frequency. Students that identified as exercising at a high level of frequency (daily or 4-6 x week) had significantly higher wellness scores than those that reported exercising moderately ( $2 \mathrm{x}$ week or $3 \mathrm{x}$ week) on eating, $\mathrm{F}(1,912)=6.09, p<.01$, and moving, $\mathrm{F}(1,912)=30.94, p<.0001)$. No significant differences were detected on the other wellness dimensions for post-scores.

High vs. low levels of exercise. One-way ANOVAs were run, per dimension, to see if post-semester wellness scores differed by exercise frequency, comparing high levels of exercise frequency to low levels of exercise frequency. Students that identified as exercising at a high level of frequency (daily or 4-6 x week) had significantly higher wellness scores than those that reported exercising at a low level of frequency ( $1 \mathrm{x}$ week or $1 \mathrm{x}$ month; Table 7$)$.

Table 7

Post-High Frequency vs. Post-Low Frequency Exercise

\begin{tabular}{|c|c|c|c|c|c|c|}
\hline \multirow{2}{*}{$\begin{array}{l}\text { Dimensions } \\
(\mathrm{N}=392)\end{array}$} & \multicolumn{2}{|c|}{ High Frequency } & \multicolumn{2}{|c|}{ Low Frequency } & \multirow[b]{2}{*}{$F$} & \multirow[b]{2}{*}{$p$} \\
\hline & $\underline{\text { Mean }}$ & $\underline{\mathrm{SD}}$ & $\underline{\text { Mean }}$ & $\underline{\mathrm{SD}}$ & & \\
\hline \multicolumn{7}{|l|}{ Self-Resp \& Love } \\
\hline & 80.73 & 13.34 & 78.19 & 12.97 & 6.06 & $.01 *$ \\
\hline Breathing & 73.73 & 17.79 & 67.67 & 17.67 & 19.03 & $.0001 * * *$ \\
\hline Sensing & 77.27 & 14.77 & 73.94 & 14.94 & 8.20 & $.004 * *$ \\
\hline Eating & 70.56 & 17.64 & 60.85 & 18.40 & 47.70 & $.0001 * * *$ \\
\hline Moving & 80.26 & 15.10 & 64.86 & 18.49 & 140.67 & $.0001 * * *$ \\
\hline Feeling & 76.37 & 17.07 & 71.24 & 17.33 & 14.57 & $.0001 * * *$ \\
\hline Thinking & 75.68 & 16.69 & 70.60 & 17.48 & 14.56 & $.0001 * *$ \\
\hline Playing \& Working & 77.40 & 16.82 & 70.76 & 17.21 & 24.93 & $.0001 * * *$ \\
\hline Communicating & 81.83 & 14.60 & 78.92 & 13.47 & 6.92 & $.009 * *$ \\
\hline Intimacy & 83.74 & 15.06 & 79.96 & 14.48 & 10.61 & $.001 * *$ \\
\hline Finding Meaning & 78.80 & 16.09 & 72.49 & 17.59 & 23.24 & $.0001 * * *$ \\
\hline Transcending & 78.14 & 17.15 & 71.94 & 17.90 & 20.64 & $.0001 * * *$ \\
\hline
\end{tabular}

Note. $*$ indicates $p<.01, * *$ indicates $p<.001, * * *$ indicates $p<.0001$

Moderate vs. low levels of exercise. One-way ANOVAs were run, per dimension, to see if post-semester wellness scores differed by exercise frequency, comparing moderate level of exercise frequency to low levels of exercise frequency. Students that identified as exercising at a moderate level of frequency had significantly higher wellness scores than those that reported exercising at a low level of frequency (Table 8). 
Table 8

Post-Moderate Frequency vs. Post-Low Frequency Exercise

\begin{tabular}{|c|c|c|c|c|c|c|}
\hline \multirow[t]{2}{*}{$\begin{array}{l}\text { Dimensions } \\
(\mathrm{N}=392)\end{array}$} & \multicolumn{2}{|c|}{$\begin{array}{l}\text { Moderate } \\
\text { Frequency }\end{array}$} & \multicolumn{2}{|c|}{ Low Frequency } & \multirow[b]{2}{*}{$F$} & \multirow[b]{2}{*}{$p$} \\
\hline & $\underline{\text { Mean }}$ & $\underline{\mathrm{SD}}$ & $\underline{\text { Mean }}$ & $\underline{\mathrm{SD}}$ & & \\
\hline \multicolumn{7}{|l|}{ Self-Resp \& Love } \\
\hline & 80.31 & 11.94 & 78.19 & 12.97 & 5.38 & $.02 *$ \\
\hline Breathing & 72.40 & 15.97 & 67.67 & 17.67 & 14.81 & $.0001 * * *$ \\
\hline Sensing & 76.73 & 14.06 & 73.94 & 14.94 & 6.86 & $.009 * *$ \\
\hline Eating & 67.72 & 16.89 & 60.85 & 18.40 & 28.26 & $.0001 * * *$ \\
\hline Moving & 74.40 & 16.25 & 64.86 & 18.49 & 56.87 & $.0001 * * *$ \\
\hline Feeling & 75.37 & 15.98 & 71.24 & 17.33 & 11.51 & $.001 * *$ \\
\hline Thinking & 74.72 & 15.34 & 70.60 & 17.48 & 11.90 & $.001 * *$ \\
\hline Playing \& Working & 75.99 & 15.73 & 70.76 & 17.21 & 18.87 & $.0001 * * *$ \\
\hline Communicating & 81.49 & 13.65 & 78.92 & 13.47 & 6.53 & $.01 *$ \\
\hline Intimacy & 83.05 & 14.89 & 79.96 & 14.48 & 8.20 & $.004 * *$ \\
\hline Finding Meaning & 77.43 & 15.75 & 72.49 & 17.59 & 16.54 & $.0001 * * *$ \\
\hline Transcending & 77.00 & 15.64 & 71.94 & 17.90 & 17.25 & $.0001 * * *$ \\
\hline
\end{tabular}

Note. $*$ indicates $p<.01, * *$ indicates $p<.001, * * *$ indicates $p<.0001$

High frequency of exercise pre/post. Twelve paired-sample $t$-tests were conducted to see if there were significant changes in dimension scores from the beginning to the end of the semester in those who reported engaging in a high frequency of exercise. A significant increase in wellness scores was seen across dimensions (Table 9).

Table 9

High Frequency of Exercise Scores Pre/Post

\begin{tabular}{|c|c|c|c|c|c|c|c|}
\hline $\begin{array}{l}\text { High Freq of } \\
\text { Exercise } \\
(\mathbf{N}=392)\end{array}$ & $\begin{array}{l}\text { Pre } \\
\text { Mean }\end{array}$ & $\underline{\mathrm{SD}}$ & Post & $\underline{\mathrm{SD}}$ & t-value & $p$ & $d$ \\
\hline \multicolumn{8}{|l|}{ Self-Resp \& Love } \\
\hline & 75.09 & 12.06 & 80.73 & 13.34 & 8.78 & $.0001 * * *$ & 0.44 \\
\hline Breathing & 58.88 & 18.09 & 73.73 & 17.79 & 17.37 & $.0001 * * *$ & 0.83 \\
\hline Sensing & 67.40 & 14.54 & 77.27 & 14.77 & 13.72 & $.0001 * * *$ & 0.67 \\
\hline Eating & 60.73 & 18.20 & 70.56 & 17.64 & 11.83 & $.0001 * * *$ & 0.59 \\
\hline Moving & 73.75 & 14.76 & 80.26 & 15.10 & 8.90 & $.0001 * * *$ & 0.44 \\
\hline Feeling & 66.98 & 16.80 & 76.37 & 17.07 & 11.67 & $.0001 * * *$ & 0.55 \\
\hline Thinking & 65.32 & 17.13 & 75.68 & 16.69 & 12.69 & $.0001 * * *$ & 0.61 \\
\hline
\end{tabular}




$\begin{array}{llllllll}\text { Playing \& Working } & 67.77 & 16.93 & 77.40 & 16.82 & 11.96 & .0001^{* * *} & 0.61 \\ \text { Communicating } & 76.71 & 13.92 & 81.83 & 14.60 & 7.42 & .0001^{* * *} & 0.36 \\ \text { Intimacy } & 78.40 & 14.57 & 83.74 & 15.06 & 7.18 & .0001^{* * *} & 0.36 \\ \text { Finding Meaning } & 71.55 & 16.82 & 78.80 & 16.09 & 9.16 & .0001^{* * *} & 0.44 \\ \text { Transcending } & 68.50 & 17.21 & 78.14 & 17.15 & 12.53 & .0001^{* * *} & 0.56\end{array}$

Note. $*$ indicates $p<.01, * *$ indicates $p<.001, * * *$ indicates $p<.0001$

Moderate Frequency of Exercise. Twelve paired-sample $t$-tests were conducted to see if there were significant changes in dimension scores from the beginning to the end of the semester in those who reported engaging in a moderate frequency of exercise. Results showed significant increases in all 12 dimensions from pre- to postassessment (Table 10). All 12 dimensions showed larger effect sizes as well.

Table 10

Moderate Frequency of Exercise Wellness Scores Pre/Post

\begin{tabular}{|c|c|c|c|c|c|c|c|}
\hline \multirow{2}{*}{$\begin{array}{lll}\text { Moderate } & \text { Freq of } \\
\text { Exercise } & & \\
(\mathrm{N}=521) & & \end{array}$} & \multicolumn{2}{|l|}{ Pre } & \multicolumn{2}{|l|}{ Post } & \multirow[b]{2}{*}{ t-value } & \multirow[b]{2}{*}{$p$} & \multirow[b]{2}{*}{$d$} \\
\hline & $\underline{\text { Mean }}$ & $\underline{\mathrm{SD}}$ & Mean & $\underline{\text { SD }}$ & & & \\
\hline \multicolumn{8}{|l|}{ Self-Resp \& Love } \\
\hline & 72.31 & 11.94 & 80.31 & 11.94 & 14.41 & $.0001 * * *$ & 0.67 \\
\hline Breathing & 55.99 & 16.30 & 72.40 & 15.97 & 23.97 & $.0001 * * *$ & 1.02 \\
\hline Sensing & 65.64 & 13.80 & 76.73 & 14.06 & 18.34 & $.0001 * * *$ & 0.80 \\
\hline Eating & 54.40 & 16.21 & 67.72 & 16.89 & 18.23 & $.0001 * * *$ & 0.80 \\
\hline Moving & 60.27 & 16.48 & 74.40 & 16.25 & 19.26 & $.0001 * * *$ & 0.86 \\
\hline Feeling & 65.89 & 14.67 & 75.37 & 15.98 & 14.36 & $.0001 * * *$ & 0.62 \\
\hline Thinking & 62.87 & 15.41 & 74.72 & 15.34 & 17.78 & $.0001 * * *$ & 0.77 \\
\hline Playing \& Working & 64.10 & 16.55 & 75.99 & 15.73 & 17.77 & $.0001 * * *$ & 0.74 \\
\hline Communicating & 76.02 & 13.41 & 81.49 & 13.65 & 10.59 & $.0001 * * *$ & 0.63 \\
\hline Intimacy & 77.52 & 14.26 & 83.05 & 14.89 & 9.90 & $.0001 * * *$ & 0.38 \\
\hline Finding Meaning & 67.87 & 15.48 & 77.43 & 15.75 & 15.68 & $.0001^{* * *}$ & 0.61 \\
\hline Transcending & 67.11 & 15.66 & 77.00 & 15.64 & 15.79 & $.0001 * * *$ & 0.63 \\
\hline
\end{tabular}

Note. $*$ indicates $p<.01, * *$ indicates $p<.001, * * *$ indicates $p<.0001$

Low frequency of exercise. Twelve paired-sample $t$-tests were conducted to see if there were significant changes in dimension scores from the beginning to the end of the semester in those who reported engaging in a low frequency of exercise. Results showed significant increases in all 12 dimensions from pre- to post-assessment (Table 11). All 12 dimensions showed larger effect sizes as well. 
Table 11

Low Frequency of Exercise Wellness Scores Pre/Post

\begin{tabular}{|c|c|c|c|c|c|c|c|}
\hline $\begin{array}{l}\text { Low Freq of } \\
\text { Exercise } \\
(\mathrm{N}=280)\end{array}$ & $\begin{array}{l}\text { Pre } \\
\text { Mean }\end{array}$ & $\underline{\mathrm{SD}}$ & $\begin{array}{l}\text { Post } \\
\text { Mean }\end{array}$ & $\underline{\mathrm{SD}}$ & t-value & $p$ & $d$ \\
\hline \multicolumn{8}{|l|}{ Self-Resp \& Love } \\
\hline & 69.54 & 13.33 & 78.19 & 12.97 & 10.56 & $.0001 * * *$ & 0.66 \\
\hline Breathing & 50.62 & 17.05 & 67.67 & 17.67 & 15.71 & $.0001 * * *$ & 0.98 \\
\hline Sensing & 61.32 & 15.18 & 73.94 & 14.94 & 13.48 & $.0001 * * *$ & 0.84 \\
\hline Eating & 45.41 & 15.53 & 60.85 & 18.40 & 16.02 & $.0001 * * *$ & 0.91 \\
\hline Moving & 43.44 & 17.03 & 64.86 & 18.49 & 19.53 & $.0001 * * *$ & 1.21 \\
\hline Feeling & 60.46 & 16.63 & 71.24 & 17.33 & 11.38 & $.0001 * * *$ & 0.63 \\
\hline Thinking & 56.49 & 15.99 & 70.60 & 17.48 & 13.66 & $.0001 * * *$ & 0.84 \\
\hline \multicolumn{8}{|l|}{ Playing } \\
\hline \&Working & 56.39 & 14.09 & 70.76 & 17.21 & 14.93 & $.0001 * * *$ & 0.91 \\
\hline Communicating & 71.00 & 14.61 & 78.92 & 13.47 & 9.53 & $.0001 * * *$ & 0.56 \\
\hline Intimacy & 72.26 & 16.98 & 79.96 & 14.48 & 8.58 & $.0001 * * *$ & 0.42 \\
\hline Finding Meaning & 61.21 & 17.95 & 72.49 & 17.59 & 11.23 & $.0001 * * *$ & 0.63 \\
\hline Transcending & 59.40 & 16.85 & 71.94 & 17.90 & 13.07 & $.0001 * * *$ & 0.72 \\
\hline
\end{tabular}

Note. $*$ indicates $p<.01, * *$ indicates $p<.001, * * *$ indicates $p<.0001$

\section{Changes in Motivation for Each Wellness Dimension}

Multiple simple linear regressions were run to predict changes in wellness scores based on the changes in motivation for each wellness dimension. A significant regression equation was found for self-responsibility, $\mathrm{F}(1,1191)=100.59$, $p=.001, \mathrm{R}^{2}=0.08$; breathing, $\left.\mathrm{F}(1,1191)=121.06, p=.001\right), \mathrm{R}^{2}=.09$; sensing, $\mathrm{F}(1,1191)=88.47, p=.001, \mathrm{R}^{2}=$ .07 ; eating, $\mathrm{F}(1,1191)=58.12, p=.001, \mathrm{R}^{2}=.05$; moving, $\mathrm{F}(1,1191)=77.44, p=.001, \mathrm{R}^{2}=.06$; feeling, $\mathrm{F}(1,1191)$ $=51.60, p=.001, \mathrm{R}^{2}=.04$; thinking, $\mathrm{F}(1,1191)=42.00, p=.001, \mathrm{R}^{2}=.03$; playing $\mathrm{F}(1,1191)=34.71, p=.001, \mathrm{R}^{2}$ $=.03$; communicating, $\mathrm{F}(1,1191)=62.27, p=.001, \mathrm{R}^{2}=.05$; intimacy, $\mathrm{F}(1,1191)=33.67, p=.001, \mathrm{R}^{2}=.03$; finding meaning, $\mathrm{F}(1,1191)=47.20, p=.001, \mathrm{R}^{2}=.04$; and transcending, $\mathrm{F}(1,1191)=129.15, p=.001, \mathrm{R}^{2}$ of .10 .

A simple linear regression was also run to predict total change in wellness scores based on total changes in motivation. Wellness change scores for each dimension were added to create a total sum score, as were motivation change scores. This was done to predict changes in overall wellness scores based on overall changes in motivation. A significant regression equation was found, $\mathrm{F}(1,1191)=121.26, p=.001, \mathrm{R}^{2}=.09$. 


\section{DISCUSSION}

\section{Summary of Findings}

Overall, these results demonstrated that college students had significant increases in all 12 dimensions of wellness and motivation from the start of the semester to the end of the semester. Both males and females also showed significant increases in ratings of wellness from the start of the semester to the end of the semester. Students who engaged in different frequencies of exercise also showed improvements in scores from the start of the semester to the end of the semester.

These outcomes show promise that a PED 101 course can be designed to help move students in the direction of wellness. Cardinal (2014) has argued for a well-rounded approach to teaching and assessing wellness in college students. The pre/post outcomes provide evidence that teaching students about wellness can change wellness and motivation scores over the course of a semester. In this study, different demographic variables were examined to see if there were changes for subgroups of gender and frequency of exercise from the beginning of the semester (preassessment) to the end of the semester (post-assessment). As suggested by our results, one possible reason for the successful increase in wellness scores and motivation scores might be the interaction that motivation is having on wellness.

Researchers have recommended that we should be assessing student wellness and education beyond health-based outcomes (e.g., exercise and weight) (Cardinal, Park, Kim, \& Cardinal, 2015). This study has attempted to address some of these concerns by not only examining pre/post outcomes from 12 different dimensions of wellness, but the authors also looked to examine how motivation may play a role in changes of wellness scores throughout a semester. The results from this study have confirmed the previously stated hypothesis that overall wellness scores and motivation would increase from the start of the semester to the end of the semester. These results also confirmed the hypothesis that males and females would both show significant increases in wellness scores and students with any frequency of exercise could improve in wellness ratings from the start of the semester to the end of the semester. These results provide further support to Travis's (1981) argument that wellness is more fluid than static. This study built upon Lothes' and Nanney's (2017) research by examining pre- and post- assessments of the Wellness Inventory. The results from this study are similar to Lothes' (2020) outcomes of pre- and post- wellness assessments in a group of college students.

Another interesting result is that no matter how participants rated themselves in terms of exercise frequency, they showed improvements in all 12 dimensions. These results also confirm Cardinal and colleagues' (2015) suggestion that assessment of wellness needs to go beyond health-based outcomes as even the self-reported low exercise frequency groups showed significant improvements in wellness. While participants engaged in high to moderate levels of exercise frequency may have more tools readily available to continue their wellness journey, moving forward, health educators should be mindful that education on these matters plays just as much a role in moving them forward as it does individuals engaging in lower levels of exercise frequency.

As Cardinal et al. (2015) and Errisuriz, Golaszewski, Born, and Bartholomew (2009) have recommended in their writings, this study has assessed student wellness and education beyond that of just health outcomes (e.g., exercise and weight). The results from this study have confirmed the previously stated hypothesis that overall wellness scores would increase from the start of the semester to the end of the semester and that motivation scores would also 
increase from the start of the semester to the end of the semester. These results also confirmed the hypothesis that males and females would both show significant increases in wellness scores.

Surprisingly, even students that self-reported low levels of exercise frequency showed significant increases in wellness scores from the start of the semester to the end of the semester. This could possibly be explained by the relationship that was discovered between motivation and wellness scores. It is understandable that even if someone is not exercising frequently, they are motivated to change their levels of wellness and as a result will still see wellness scores increases. This also provides more support for Cardinal's (2014) argument, i.e., as wellness researchers we need to look beyond exercise as being one of the main factors being assessed to determine wellness in people.

This study took Lothes' and Nanney's (2019) research a step further by examining pre- and post- assessments of the Wellness Inventory (Travis, 1981) and motivation. Lothes and Nanney (2019) only examined differences between demographic variables at the end of the semester using the Wellness Inventory. However, this study does confirm some of Lothes' and Nanney's (2019) findings like gender differences existing in the different dimensions of wellness. Therefore, it is even more imperative that wellness researchers study wellness on a multi-dimensional level to understand how different aspects of wellness may play a role in different people's lives.

These results also show that engaging students in physical education courses that take a holistic approach to wellbeing do help to improve multiple dimensions of wellbeing in different demographics. Future studies should examine more effective ways to specifically target wellness dimensions and motivation factors that may help to compliment wellness dimensions that speak to different demographic groups.

Another interesting result is that regardless of where students reported their levels of frequency of exercise all groups (high to low) showed significant increases in wellness scores over the semester. These outcomes support Cardinal's (2015) call to action that we need to assess wellness in people beyond the traditional metrics, like eating and exercise. These results support the concept that focusing on wellness for a college student population should include all student demographics and not just ones that are engaging in low frequency exercise habits. While exercise frequency can help facilitate wellness, being aware of students' motivations and finding effective ways to increase motivation for students also has been shown to play a role in wellness dimension increases.

In summary, as health educators it is our responsibility to take students from where they are in exercise frequency and motivation and attempt to move them toward wellness as Travis (1981; Travis \& Ryan 2004) has pointed out. Through education on the 12 dimensions of wellness, we can help sow the seeds of health and wellbeing for future generations even after graduation.

\section{LIMITATIONS}

Limitations for this study include that there was no control group to see if these differences are the result of the physical education course or if it is just a natural occurrence of being in college. It is recommended that future studies adopt an experimental or quasi-experimental approach by including a control group that is not exposed to a physical education course. It is also recommended to try to capture pre-physical education students for an assessment and to potentially follow them for longitudinal data collection. In this instance, data collection would start during the semesters where they have not taken a physical education course to the semester where they were taking a physical education course. Ambitious researchers could also consider tracking students longitudinally after a physical education course to see if trends were sustained across the college years. 
Another limitation, like many survey-based projects, is that the data were based on student self-reports. Selfreported data has the potential for contamination through skewed information. However, the changes on most demographics indicate that $1,000+$ students (the lowest demographic group being $\mathrm{N}=280$ ) is probably a sufficiently large sample to reduce any effects of misreporting ratings of wellbeing. Another suggestion would be to try this same type of educational protocol with individuals in the general public to see if these matters of wellness show changes when individuals are not required to do the work as in the form of class work for course credit.

\section{CONCLUSION}

Current trends in college student health are showing an increase in sedentary lifestyles for both college students and adults after graduation. As the CDC (2018) has stated, the current generation will be the first in a long time to have a shorter life expectancy than the generations before them. It is important that colleges and universities offer physical education and wellbeing courses to help set the foundation of effective and healthy living after leaving college and potentially curbing this prediction. Setting a foundation for effective health and wellness habits in college may influence lifestyle behaviors across the lifespan. With current research and trends showing that sedentary lifestyles correlate with negative health and illness consequences, it is imperative that we as health educators provide the knowledge of what effective healthy behaviors are and what unhealthy behaviors look like to students. It is recommended that health educators emphasize the importance of a more holistic approach to wellbeing and to not only focus on physical activity and eating well. This would include instructional materials and practices beyond the classroom that help promote students to build lifelong habits of health and wellness. Moving college students towards the direction of wellness as indicated in John Travis's Wellness Continuum (Travis, 1981) can help set the tone for healthy future adults. 


\section{REFERENCES}

American College Health Association (ACHA; 2017). National College Health Assessment II: Undergraduate Student Reference Group Data Report. Retrieved from https://www.acha.org/documents/ncha/NCHAII_FALL_2017_REFERENCE_GROUP_DATA_REPO RT.pdf

American College Health Association (ACHA; 2010). Healthy Campus 2010: Make it happen. Baltimore, MD

Baldwin, D., Towler, K., Oliver, M., \& Datta, S. (2017). An examination of college student wellness: A research and liberal arts perspective. Health Psychology Open, 1. https://doi.org/10.1177/2055102917719563

Bandura, A. (1977) Self-efficacy: Toward a unifying theory of behavioral change. Psychological Review, 84, 191-215. https://doi.org/10.1037/0033-295x.84.2.191

Beauchemin, J., Gibbs, T., \& Granell, P. (2018). Wellness promotion courses in university settings: A review of the outcome research. Building Healthy Academic Communities Journal. 2(1), 36-49. https://doi.org/10.18061/bhac.v2i1.6344

Buckworth, J., \& Nigg, C. (2004). Physical activity, exercise, and sedentary behavior in college students. Journal of American College Health, 53, 28-34. https://doi.org/10.3200/jach.53.1.28-34

Burris, M., Brechting, M., Salsman, \& Carlson C. (2009). Factors associated with the psychological wellbeing and distress of university students. Journal of American College Health, 5, 536-544, https://doi.org/10.3200/JACH.57.5.536-544

Cardinal, B. (2014). Physical activity psychology research: Where have we been? Where are we going? Kinesiology Review, 3(1), 44-52. https://doi.org/10.1123/kr.2014-0036

Cardinal, B., Park, E., Kim, M., \& Cardinal, M. (2015). If exercise is medicine, where is exercise in medicine? Review of U.S. medical education curricula for physical activity-related content. Journal of Physical Activity \& Health, 12(9), 1336-1343. https://doi.org/10.1123/jpah.2014-0316

Centers for Disease Control and Prevention. (2018). CDC Director's Media Statement of U.S. Life Expectancy. Retrieved from https://www.cdc.gov/media/releases/2018/s1129-US-life-expectancy.html

Downes, L. (2015). Physical activity and dietary habits of college students. The Journal of Nurse Practitioners, 11(2), 192-98. https://doi.org/10.1016/j.nurpra.2014.11.015

Edelman, C.L., \& Mandle, C.L. (2017). Health promotion throughout the lifespan. $9^{\text {th }}$ ed. St. Louis: Mosby.

Engel, G. (1977). The need for a new medical model: A challenge for biomedicine. Science, 196, 129-136. https://doi.org/10.4135/9781446221129.n3

Engel, G. (1980). The clinical application of the biopsychosocial model. American Journal of Psychiatry, 137, 535-544. https://doi.org/10.1093/med/9780190628871.003.0002

Errisuriz, V., Golaszewski, N., Born, K., \& Bartholomew, J. (2018). Systematic review of physical education-based physical activity interventions among elementary school children. Journal of Primary Prevention, 39(3), 303-327. https://doi.org/10.1007/s10935-018-0507-x 
Gieck, M., \& Olsen, M. (2007). Holistic wellness as a means to developing a lifestyle approach to health behavior among college students. Journal of American College Health, 56(1), 29-36.

https://doi.org/10.3200/JACH.56.1.29-36

Gordon, J.S. (1990). Holistic medicine and mental health practice: Toward a new synthesis. American Journal of Orthopsychiatry, 60(3), 357-369. https://doi.org/10.1037/h0079185

Hettler, B. (1984). Wellness: Encouraging a lifetime pursuit of excellence. Health Values, 8, 13-17.

Hultquist, C., Duckham, R., Stinson, C., \& Thompson, D. (2009). College physical activity is related to mid-life activity levels in women. Journal of Exercise Physiology-online, 12(4), 1-7.

Keating, X., Guan, J., Pinero, J., \& Bridges, D. (2005). A meta-analysis of college students' physical activity behaviors. Journal of American College Health, 54(2), 116-25. https://doi.org/10.3200/jach.54.2.116-126

Keyes, C., Eisenberg, D., Perry, G., Dube, S., Kroenke, K., \& Dhingra, S. (2012). The relationship of level of positive mental health with current mental disorders in predicting suicidal behavior and academic impairment in college students. Journal of American College Health, 60, 126-132. https://doi.org/10.1080/07448481.2011.608393

Keyes, C., \& Grzywacz, J. (2005). Health as a complete state: The added value in work performance and healthcare costs. Journal of Occupational and Environmental Medicine, 47, 523-532. https://doi.org/10.1097/01.jom.0000161737.21198.3a

Keyes, C., \& Simoes, E. (2012). To flourish or not: Positive mental health and all-cause mortality. American Journal of Public Health, 102, 2164-2172. https://doi.org/10.2105/AJPH.2012.300918

Kirsten, T.G., Van der Walt, H.S.J.L., \& Viljoen, C.T. (2009). Health, wellbeing and wellness: An anthropological eco-systemic approach. Health SA Gesondheid, 14(1), 1-7. https://doi.org/10.4102/hsag.v14i1.407

Lothes, J. (2020). Teaching wellness in a college physical education course: Pre/post outcomes over the semester. Building Healtby Academic Communities Journal, 4(1). https://doi.org/10.18061/bhac.v4i1.7267

Lothes, J., \& Nanney, L. (2019). Using the wellness inventory to assess health and wellbeing in college students at the end of the semester. Journal of American College Health, 1-8. https://doi.org/10.1080/07448481.2018.1549047

Lyubomirsky, S., King, L., \& Diener, E. (2005). The benefits of frequent positive affect: Does happiness lead to success? Psychological Bulletin, 131, 803-885. https://doi.org/10.1037/0033-2909.131.6.803

Myers, J., \& Sweeney, T. (2004). The indivisible self: An evidence-based model of wellness. Journal Individual Psychology, 60, 234-244.

Nanney, L. (2019). Physical activity and wellness. TopHat: Toronto Canada.

Rouse, P., \& Biddle, S. (2009). An ecological assessment of the physical activity and sedentary behavior patterns of university students. Journal of Health Education, 69(1), 116-125. https://doi.org/10.1177/0017896910363145

Ryan, R., \& Deci, E. (2017). Self-Determination Theory: Basic Psychological Needs, in Motivation, Development, and Wellness. New York, NY: Guilford Press. https://doi.org/10.1521/978.14625/28806 
Seligman, M. E. P. (1975). Helplessness: On Depression Development and Death. Freeman and Co.: San Francisco.

Steptoe, A., Deaton. A., \& Stone, A. (2015). Subjective wellbeing, health, and ageing.

The Lancet, 385, 640-648. https://doi.org/10.1016/s0140-6736(13)61489-0

Travis, J.W. (1981). The Wellness Inventory. Mill Valley, CA: Wellness Associates.

Travis J.W., \& Ryan R.S. (1981). Wellness workbook $1^{\text {st }}$ ed. Berkeley: Ten Speed Press.

Travis J.W., \& Ryan R.S. (2004). Wellness workbook $3^{\text {rd }}$ ed. Berkeley: Ten Speed Press.

US Department of Health and Human Services. (DHHS; 2019). Physical activity guidelines for Americans. $2^{\text {nd }}$ ed. Washington, DC: US Government Printing Office.

Vroom, V.H. (1964). Work and motivation. New York: Wiley \& Sons, Inc.

Wahl-Alexander, Z., \& Chomentowski, P. (2018). Impact of a university physical conditioning sports education season on student' fitness levels. Health Education Journal, 21, 1-9. https://doi.org/10.1177/0017896918776340

World Health Organization (WHO). (2010). Global recommendations on physical activity for health. Switzerland.

Yerkes, R. \& Dodson, J. (1908). The relation of strength of stimulus to rapidity of habit-formation. Journal of Comparative Neurology and Psychology, 18(5), 459-82. https://doi.org/10.1002/cne.920180503

Address author correspondence to:

John Lothes II, LPA, Ed.D.

Lecturer

University of North Carolina Wilmington

School of Health and Applied Human Sciences

Physical Activity and Wellness (PED 101)

601 S. College Rd.

Wilmington, NC 28403

lothesj@uncw.edu

\section{Conflict of Interest Disclosure}

The author has no conflicts of interest to report. The author confirms that the research presented in this article met the ethical guidelines, including adherence to the legal requirements, of the United States and received approval from the Institutional Review Board of the University of North Carolina Wilmington (18-0232). 